\title{
Factors associated with obesity among Saudi women of reproductive age in Jeddah City
}

\author{
Alharbi $\mathrm{MM}^{\star}$ and Robert T Jackson \\ Department of Nutrition and Food Science, Skinner Hall, University of Maryland, College Park, MD, USA
}

${ }^{*}$ Corresponding author: Alharbi MM, Department of Nutrition and Food Science, 0119C Skinner Hall, University of Maryland, College Park, MD USA 20742-7521, Tel: 240-463-5044, E-mail: malharbi.sa@gmail.com

Citation: Alharbi MM, Robert T Jackson (2017) Factors associated with obesity among Saudi women of reproductive age in Jeddah City. J Obes Overweig 3(1): 106. doi: 10.15744/2455-7633.3.106

Received Date: April 06, 2017 Accepted Date: May 17, 2017 Published Date: May 19, 2017

\begin{abstract}
Background: Previous studies have shown that women who are overweight or obese are at risk for adverse reproductive outcomes, including infertility, gestational diabetes, and hypertensive disorders of pregnancy. However, information surrounding the risk factors for obesity among Saudi women of reproductive age is deficient due to the limited number of studies that assessed obesity prevalence among them.

Objective: To identify how socio-demographic, parity, eating habits (EHs), family history, and physical activity (PA) factors correlate with obesity assessed by Body Mass Index (BMI) and Waist Circumference (WC) in a representative sample of Saudi women attending Jeddah Primary Health Centers (JPHCCs).

Methods: A cross-sectional study was conducted in 2014 using a stratified two-stage cluster sampling design that consisted of 408 Saudi women (15-49 years) attending 12 JPHCCs. The sampling weight and design effect were incorporated into the analysis. BMI and WC data were collected through previously validated interviews. Additionally, the anthropometric measurements (BMI and WC) were defined according to the WHO criteria.

Results: The prevalence of general and abdominal obesity among the study population was $33.5 \%$ and $25.1 \%$ respectively. Age, family history of obesity, and EHs were significant positive predictors for both general and abdominal obesity, while a fast food habit was a significant positive predictor for general obesity only. Being a student, being in a higher-income level, and eating three main meals/day were the three predictors with significant negative associations with abdominal obesity, while hours of sitting had significant positive associations.

Conclusion: The prevalence of general and abdominal obesity were remarkably high in Saudi women of reproductive age attending Jeddah PHCCs. Our results suggest that age and family history of obesity are crucial factors that positively associated with elevated risks of developing both types of obesity.

Keywords: Body Mass Index (BMI); Waist Circumference (WC); Obesity; Abdominal Obesity; Risk Factors; Saudi; Reproductive-Aged Women

List of Abbreviations: BMI: Body mass index; WC: waist circumference; PHCCs: primary health care centers; PA: physical activity; EHs: eating habits; PSU's: Primary Sampling Units; PPS: Probabilities Proportional to their Size; IPAQ: International Physical Activity Questionnaire; MET-Min/week: Metabolic Equivalent Task minutes per week; WHO: World Health Organization standards; CVD: cardiovascular disease
\end{abstract}

\section{Introduction}

Obesity, an increasing worldwide trend, constitutes a major health problem [1]. The prevalence of obesity has generally found to be higher among women than among men [2]. Similarly, the prevalence of obesity in Saudi Arabia has increased, and it is significantly higher in women than men. Based on the latest Saudi National Health Survey (2013), the prevalence of obesity in Saudi Arabia for those 15 years of age and older was significantly higher among women (33.5\%) when compared to men (24.1\%) [3]. An earlier study done in Jeddah City (1994), the most urbanized city in the western part of Saudi Arabia, indicated high rates of overweight and obesity (64.3\%, BMI $\geq 25)$ among adolescent and adult Saudi women between the ages 11 through 70 , attending primary health centers in Jeddah City [4]. The prevalence of overweight and obesity (52.6\%) among Saudi women of reproductive age (16-45 years old) in Riyadh City, Saudi Arabia [5] was similar to results (51\%) obtained from national representative data collected over 10 years among all U.S women of reproductive age (15-49years old) [6]. 
Obesity has become a common issue among Saudi women due to different factors, such as socio-demographic, family history of obesity, and lifestyle factors (e.g. age, marital status, parity, eating habits (EHs), and physical activity (PA)) [3-5,7-12]. Among Saudi women (aged 15 years or older), the latest Saudi National Health Survey found the risk of obesity increased with age, marital status, history of chronic conditions and hypertension [3]. In Jeddah City, Western Province of Saudi Arabia, Khashoggi (1994) found five variables were significant predictors for women's obesity (11-70 years): age, marital status, number of servants, childbearing, and parity [4]. Among women of reproductive age (15-45 years), Al-Malki (2003) indicated a positive correlation between age and weight, and age and BMI. A significant difference was observed in the results of single (never married) and married women, particularly those who were students; among the single women only $20.5 \%$ were overweight, $9.12 \%$ were obese, while in married women the frequency increased to 43.0\%, and 29\% [5]. A number of studies in Eastern Mediterranean Region (EMR) countries have shown that the employment status of women is significantly associated with weight gain. These studies showed that working women were less likely to be overweight than non-working women. Furthermore, the rate of obesity in unemployed Saudi women was 79\%, compared to 53\% in employed women [11].

During the past four decades, EHs in Saudi Arabia have changed markedly, with the changes in lifestyle and reduced PA behaviours. In fact, Western fast food, which has high levels of fat, sugars, sodium, and cholesterol, is now being consumed in large amounts $[11,13]$. Moreover, the Saudi National Nutrition Survey disclosed that eating unhealthy foods (e.g., fried foods, fewer fruits and vegetables) and high-calorie snacks (e.g., cake, donuts, or chips) is becoming a common practice among Saudi people [7]. Other eating antecedents in common demonstrated that the obese were less likely to eat at selected times and more often indulged in eating while watching TV. The severely obese groups chose to skip main meals more frequently $(\mathrm{P}=0.08)$, mainly the breakfast meal (62.5\%). On the other hand, as a result of fewer main meals, the severely obese group indiscriminately snacked more and ate in secret [14].

Sedentary lifestyles and PA patterns are risk factors associated with obesity. Saudis with increased urbanization, availability of cars, traffic, involvement in office work, and extreme weather, all make PA a difficult choice for Saudis [15,16]. According to data from the Saudi National Health Survey (2013) [3], the prevalence of physical inactivity was high among the Saudi population (15 years of age and older), revealing significantly higher levels of inactivity in women (75.1\%) than men (47.0\%). However, information on the levels of PA and other lifestyle practices in Saudi adult women is lacking, especially among women particularly at risk of weight gain, such as those of reproductive age.

BMI is the anthropometric measurement most widely used to assess total body fatness. In addition, it has long been recognized that BMI is a predictor of morbidity and mortality. On account of its simplicity as a measure, it has been used in epidemiological studies and is recommended as a screening tool in the clinical assessment of obesity. Although BMI has been found to be a reliable indicator of total body fat, there are limitations to the use of BMI alone to assess for adiposity in clinical practice, particularly among adults with $\mathrm{BMI} \geq 30 \mathrm{~kg} / \mathrm{m}^{2}[17,18]$. Because of these limitations of BMI, the WHO and several organizations suggest combining the measurements of BMI and waist circumference (WC) to assess obesity-related health risks [19]. WC, which is highly correlated with cardiovascular disease (CVD) risk factors, has been shown to be a strong predictor of total body fat, adipose tissue [20-22], and obesity-related health risk [19].

The reproductive age is an important feature of monitoring and addressing adverse weight transitions among women, as these transitions will have adverse effects on women's short and long-term health and their children's health [23]. However, the literature in Saudi Arabia suggests that current information about risk factors for obesity among Saudi women of reproductive age is not sufficient due to the lack of studies performed to determine obesity risk factors. Most studies focused on the male population, children and adolescents, or on women in the adolescent and college years (under the age of 24 years). Also, most of these studies used BMI rather than WC to determine obesity and its associated factors. As far as it is known, no study has explored the risk factors of obesity among Saudi women of reproductive age in Jeddah City, the most liberal, urban, and diverse city in Saudi Arabia, where the prevalence of obesity is high [4]. Therefore, the present study was planned and conducted in Jeddah City using a representative sample of Saudi women (15-49 years) who attended services at JPHCCs, to determine how socio-demographic, parity, family history of obesity, EHs, and PA factors are associated with two types of obesity - general (BMI) and abdominal (WC) obesity. Meeting this need can assist in the development of programs and policies that support national health objectives.

\section{Methods}

\section{Sample}

The study was conducted using a cross-sectional stratified two-stage cluster sampling design survey of 408 Saudi women, aged 1549 years, who attended general clinics at JPHCCs. The sampling procedure aimed to select a representative sample of women who were only seeking services at PHCCs in Jeddah City. Clinics served as Primary Sampling Units (PSU's) and were grouped into four health sector strata. In the first stage, the PHCCs (clusters) were sampled without replacement and selected (12 out of 37 centers) with Probabilities Proportional to their Size (PPS), from the list of PHCCs in survey area. The second sampling stage involved recruitment of women from the selected PHCCs (12 centers) using a systematic sampling procedure from the eligible women attending on days the sampling PHCCs (General Clinics) were visited. The first woman participant who fulfilled the inclusion 
criteria was invited to enroll in the study. Then, every third attending woman who fulfilled the criteria was selected and soon until completion of the required sample from the PHCC was achieved. However, if a selected woman did not fulfill the inclusion criteria (exclusion criteria) or refused to participate in this study, then selection proceeded to the next sample woman attending the PHCC. Subjects who were pregnant/ lactating and those having serious diseases (e.g., organ failure, transplant, ascites, cancer, and mental illness), were excluded.

Sample size was determined by performing an a-priori power analysis to determine the number of participants required to detect a small effect of design $(f 2=0.1)$ with power $=.80$, for a multiple regression with 15 predictors and hypothesis tests conducted at $a=.05$ (the power analysis was conducted with $G^{\star}$ Power 3.1.4.). The analysis indicated a sample size of 201 would be sufficient. Then, this was adjusted for clustering by multiplying this sample size by a convenient design effect of 2.0 , which indicated that a minimum of 402 women would be sufficient to accurately estimate results for the final sample. However, to selected equal number of the women from the selected health centers ( 12 centers) we increased the sample size to 408 ( 34 women /12 centers).

\section{Survey}

Participants were asked to participate in answering the survey questions as volunteers. The informed consent information was distributed to participants before participating in the study. A structured questionnaire (face-to-face interview) was used in the survey to elicit information on the socio-demographic characteristics, medical and history of chronic diseases, obstetric history, EHs, PA, and lifestyle information.

\section{Eating habits (EHs) Assessment}

EHs were assessed in the questionnaire by taking a selection of items from the reliable EHs questionnaire [24,25] while others were generated from the literature [7,10,11,14,26,27] with expert advice from nutritionists. The EHs section of the survey consisted of 15 questions (items), which were designed to investigate the actual eating behaviors of the participants in the study (see the appendix, section 4). The items referred to both healthy and unhealthy EHs as well as to behaviors. EHs were operationalized with four variables (EHs section) including: the number of regular meals eaten each day, eating fast food, consuming saturated fat, and overall EHs score. Overall EHs were assessed with a mean composite score of 14 items, which had the following response categories: always, often, sometimes, never. The 7 items of the response categories ranged from always (highest score $=4)$ to never (lowest score =1) (items from 4.2-4.8), while the scores of other 7 items were reversed (always $=1$ and never $=4$ ) (items from 4.9 to 4.15 ). The total score (56) was divided into tertiles, where the lowest tertile (score $\leq 33$ ) referred to "inadequate EHs", the medium tertile (score $\geq 34$ to 37) referred to "partially satisfactory EHs" and the highest tertile (score $\geq 38$ ) referred to "satisfactory EHs" [24]. The eating habits questionnaire (13items) that were used to determine the overall eating habits score) was piloted with 20 women (from PHCCs in Jeddah City) to test the reliability using Cronbach's alpha coefficient. The value of Cronbach's alpha coefficient for eating habits items was 0.648 , indicating an acceptable level of internal consistency [28].

\section{Physical Activity Assessment}

PA was assessed using the official Arabic short version of the International Physical Activity Questionnaire (IPAQ) [29]. IPAQ was subjected to a reliability and validity study carried out in 14 centers in 12 countries during the year 2000, and demonstrated reasonable test-retest reliability (intra-class correlations range 0.7-0.8 and inter-method validity (median $r_{s}=.67$ ) [30]. The short form of IPAQ (see the appendix, section 5) has been validated and used by numerous studies among the Saudi Arabia adult population [3,31-34]. The total weekly PA (Metabolic Equivalent Task minutes per week (MET-Min/week)) was calculated by multiplying the number of minutes spent in each activity category (low, moderate, and vigorous levels) with the specific MET score for each activity. The MET intensity values that were used to score IPAQ questions were: vigorous ( 8 METs), moderate (4 METs) and low (3.3 METs) [35]. For descriptive analysis, the PA scoring was categorized as: physically inactivate (low activity $<600$ MET-min./week), and physically active (sufficient activity $\geq 600 \mathrm{MET}-\mathrm{min}$./week).

\section{Anthropometric measurements}

Weight and height were measured on a digital scale with stadiometer (Seca 703 medical scale) (Hamburg, Germany). Weight was recorded to the nearest $100 \mathrm{gm}$ and height to the nearest $0.1 \mathrm{~cm}$. Measurements of participants were collected in a private area (exam room) and instructed them to remove excess clothing, overcoats, Hejab, Abaya, and shoes. BMI was calculated as weight divided by height squared $\left(\mathrm{kg} / \mathrm{m}^{2}\right)$, and was stratified for the purpose of analysis into two categories: non-obese and obese based on World Health Organization standards (WHO) 2012 [36]. For adult ( $\geq 20$ years old), non-obese group was defined as BMI< $25 \mathrm{kgm}^{2}$, and obese group (overweight/obese) as $\mathrm{MBI} \geq 25 \mathrm{kgm}^{2}$. For adolescents ( $\leq 19$ years old), non-obese group was defined as $\mathrm{BMI}<85$ th age-specific percentile, and obese group (overweight/obese) as BMI $\geq 85$ th age-specific percentile. Online software was used to calculate BMI age-specific percentile from height, weight, age, and sex data, based on WHO reference populations $[37,38]$. WC was measured at the mid-point between the iliac crest and lowest rib to the nearest $0.1 \mathrm{~cm}$. Then, abdominal obesity was defined as $W C>88 \mathrm{~cm}$ [37]. 


\section{Ethical approval}

Ethical approval for the study (IRB approval) was obtained from the University of Maryland, College Park (No. 539976-1), and the Ministry of Health - Jeddah Health Affairs Directorate in Saudi Arabia (No. A00118). Prior to the interview, each woman was asked to read and sign a consent form, which stated the purpose of the study, that participation was voluntary, and that women's responses were to be kept confidential.

\section{Statistical Analysis}

All analyses were based on the complex sampling design using the SPSS Complex Samples Software (Version 23.0). The complex sample design was accounted for in all analyses through the use of a sampling weight to account for unequal chances of selection, a sampling error stratum and sampling error computing unit (clinic), and a Taylor Series Linearization (TLS) method for variance estimation.

Multiple regression (using the SPSS subprogram CSGLM) and a binary logistic regression (using the SPSS subprogram CSLOGISTIC) were conducted to determine if the socio-demographic, parity, family history of chronic disease, EHs and PA were significant predictors of participants' obesity as measured by BMI and WC, respectively (Table 1). A p value $<.05$ was considered statistically significant. Age, years of education, parity, number of meals, EHs and PA were all continuous variables; occupation, marital status, income, family history of chronic disease, eating fast food, and consumed saturated fatty food were categorical. For categorical variables that have more than two levels, reference groups were assigned and dummy variables were created for the analyses. Moreover, descriptive statistics (using the SPSS subprogram CSDESCRIPTIVES) were used to describe the characteristics of the study population including mean, standard error, frequency, and percentage. Chi square tests (using the SPSS subprogram CSTABULATE) or t tests (using the SPSS subprogram CSGLM) were used to examine the associations between participant's characteristics and obesity status. In the logistic regression and Chi square analysis, the BMI levels (dependent variable) were divided into two groups: obese $\left(\mathrm{BMI} \geq 25 \mathrm{~kg} / \mathrm{m}^{2}\right)$ and non-obese $\left(\mathrm{BMI}<25 \mathrm{~kg} / \mathrm{m}^{2}\right)$.

\begin{tabular}{|c|c|c|c|c|}
\hline Variables & $\mathbf{n}(\%)^{\mathbf{b}}$ & Mean $\pm \mathrm{SE}^{\mathrm{c}}$ & P value ${ }^{\mathrm{d}}$ & P value ${ }^{e}$ \\
\hline \multicolumn{5}{|l|}{ BMI (dependent variables in logistic regression) } \\
\hline Non-obese $\left(\mathrm{BMI}<25 \mathrm{~kg} / \mathrm{m}^{2}\right)$ & $149(36.5)$ & & & \\
\hline Overweight/Obese $\left(\mathrm{BMI} \geq 25 \mathrm{~kg} / \mathrm{m}^{2}\right)$ & $259(63.5)$ & & & \\
\hline $\begin{array}{c}\text { WC (dependent variables in multiple linear } \\
\text { regression) }\end{array}$ & & $80.2( \pm 1.1)$ & & \\
\hline Occupation Status & & & .518 & $.006^{*}$ \\
\hline Housewife & $218(53.4)$ & & & \\
\hline Employed & $87(21.4)$ & & & \\
\hline Student (Reference group) & $103(25.2)$ & & & \\
\hline Income Status & & & .792 & $>.028^{*}$ \\
\hline Low Income $(<8,000 \mathrm{SAR})$ & $159(39.1)$ & & & \\
\hline Middle Income (8,000-18,000 SAR) & $216(52.8)$ & & & \\
\hline High Income (>18,000 SAR) (Reference group) & $33(8.1)$ & & & \\
\hline Marital Status & & & .137 & .081 \\
\hline Never married & $127(31.0)$ & & & \\
\hline Married & $281(69.0)$ & & & \\
\hline Fast Food Habit & $345(84.6)$ & & $.002^{*}$ & .079 \\
\hline Consume saturated fat & 194(47.5) & & .42 & .144 \\
\hline Family history of obesity & $60(14.7)$ & & $.002^{*}$ & $<.001^{*}$ \\
\hline Age & & $30.3( \pm 0.7)$ & $<.001^{\star}$ & $<.001^{\star}$ \\
\hline Years of Education & & $12.1( \pm 0.3)$ & .652 & .649 \\
\hline Parity & & $2.3( \pm 0.2)$ & .234 & .274 \\
\hline Number of meals & & $2.4( \pm 0.04)$ & .211 & $.001^{*}$ \\
\hline EHs Scores & & $37.5( \pm 0.3)$ & $.015^{*}$ & $.001^{*}$ \\
\hline PA Scores & & $953.1( \pm 0.7)$ & .521 & .388 \\
\hline Hours Sitting per day & & $2.9( \pm 0.1)$ & .418 & $.007^{*}$ \\
\hline
\end{tabular}

BMI: Body mass index; WC: waist circumference.

${ }^{a}$ Predictors used in logistic and multiple linear regression models; ${ }^{b}$ Percentage may not total to $100 \%$ due to rounding;

${ }^{\mathrm{c}}$ mean \pm standard error, ${ }^{\mathrm{d}} \mathrm{p}$ value for logistic regression model, ${ }^{\mathrm{e}} \mathrm{p}$ value for multiple linear regression model, ${ }^{*}$ significant $\mathrm{p}=<.05$.

Table 1: Potential predictors and dependent variables included in regression models ${ }^{\mathrm{a}}$ among non-pregnant Saudi women of reproductive age residing in Jeddah city, Saudi Arabia $(n=408)$ 


\section{Results}

\section{Anthropometric characteristics and prevalence of women with overweight and obesity}

Table 2 shows the anthropometric characteristics of the study participants and the prevalence of general (BMI) and abdominal (WC) obesity Based on the WHO criteria.

\begin{tabular}{|c|c|c|c|}
\hline Anthropometric characteristics & n & $\%$ of total ${ }^{a}$ & $\operatorname{Mean} \pm \mathrm{SE}^{\mathrm{b}}$ \\
\hline Height $(\mathrm{cm})($ mean \pm SE $)$ & & & $156.50 \pm 0.41$ \\
\hline Weight (kg) (mean \pm SE) & & & $67.7 \pm 1.30$ \\
\hline \multicolumn{4}{|l|}{ BMI $\left(\mathrm{kg} / \mathrm{m}^{2}\right)$ WHO cutoff } \\
\hline Underweight $(<18.5)$ & 41 & 10.1 & \\
\hline Normal (18.5-24.9) & 108 & 26.6 & \\
\hline Overweight (25-29.9) & 121 & 29.5 & \\
\hline Obese $(\geq 30)$ & 138 & 33.8 & \\
\hline $\mathrm{WC}(\mathrm{cm})($ mean $\pm \mathrm{SE})$ & & & $80.4 \pm 1.12$ \\
\hline \multicolumn{4}{|l|}{ WC $(\mathrm{cm})$ WHO cutoff } \\
\hline Normal $(<88)$ & 306 & 75.0 & \\
\hline Health Risk ( $\geq 88)$ & 102 & 25.1 & \\
\hline
\end{tabular}

BMI: Body mass index; WC: waist circumference; $\mathrm{kg}$ : kilogram; $\mathrm{m}^{2}$ : meter square; $\mathrm{cm}$ : centimeter; SE:

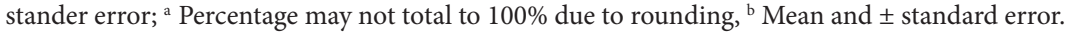

Table 2: Anthropometric characteristics of non-pregnant Saudi women of reproduction age residing in Jeddah city, Saudi Arabia $(n=408)$

\section{Socio-demographic characteristics and lifestyle factors of study participants}

Table 3 shows the socio-demographic characteristics and lifestyle factors of the study participants. The mean age' (mean \pm SE) of study participants was $30.27 \pm 0.74$, and the majority of the women were in the age group of 20-35 years (51.4\%), married (64\%), housewives (53.4\%), had more than a high school diploma (54.2\%), and belonged to low (39.1\%) or middle (52.8\%) income levels. Thirty-two percent of the women showed "satisfactory EHs", and 65\% of them engaged in moderate PA.

\begin{tabular}{|c|c|c|c|}
\hline Variables & n & $\%$ of total ${ }^{a}$ & $\operatorname{Mean} \pm \mathrm{SE}^{\mathrm{b}}$ \\
\hline Age $($ mean \pm SE $)$ & & & $30.3 \pm 0.7$ \\
\hline Adolescents (15-19yrs) & 70 & 17.3 & \\
\hline Young women (20-35yrs) & 210 & 51.4 & \\
\hline Middle aged (36-49yrs) & 128 & 31.4 & \\
\hline Education $($ mean \pm SE) & & & $12.1 \pm 0.3$ \\
\hline Less than high school & 125 & 30.7 & \\
\hline Completed high school & 99 & 24.1 & \\
\hline More than high school & 184 & 45.2 & \\
\hline \multicolumn{4}{|l|}{ Income level } \\
\hline Low income $(<7,999 \mathrm{SAR})$ & 159 & 39.1 & \\
\hline Middle income (8000-17,999SAR) & 216 & 52.8 & \\
\hline High income (> 18,000SAR) & 33 & 8.1 & \\
\hline \multicolumn{4}{|l|}{ Marital status } \\
\hline Never married & 127 & 31.1 & \\
\hline Married & 261 & 64.0 & \\
\hline Separated & 3 & 0.8 & \\
\hline Divorced & 11 & 2.7 & \\
\hline Widowed & 6 & 1.4 & \\
\hline \multicolumn{4}{|l|}{ Occupation status } \\
\hline Housewife & 218 & 53.4 & \\
\hline Employed & 87 & 21.4 & \\
\hline Student & 103 & 25.2 & \\
\hline
\end{tabular}




\begin{tabular}{|c|c|c|c|}
\hline Variables & $\mathbf{n}$ & $\%$ of total ${ }^{\mathrm{a}}$ & Mean $\pm \mathrm{SE}^{\mathrm{b}}$ \\
\hline \multicolumn{4}{|l|}{ Breastfeed } \\
\hline Yes & 247 & 94.0 & \\
\hline No & 15 & 6.0 & \\
\hline $\begin{array}{l}\text { Duration of breastfeed (months) } \\
\qquad(\text { mean } \pm \text { SE) }\end{array}$ & & & $6.7 \pm 0.5$ \\
\hline Times of parity (mean \pm SE) & & & $2.29 \pm 0.2$ \\
\hline Nulliparous & 149 & 36.5 & \\
\hline 1-2 children & 97 & 23.8 & \\
\hline 3 children & 36 & 8.7 & \\
\hline 4 and more children & 126 & 31.0 & \\
\hline \multicolumn{4}{|l|}{ Family history of chronic diseases } \\
\hline Yes & 346 & 84.7 & \\
\hline No & 62 & 15.3 & \\
\hline \multicolumn{4}{|l|}{ Women having health conditions } \\
\hline Yes & 134 & 32.9 & \\
\hline No & 274 & 67.1 & \\
\hline EHs Scores (mean \pm SE) & & & $37.5 \pm 0.27$ \\
\hline Inadequate EHs & 97 & 24.0 & \\
\hline Partially Satisfactory EHs & 122 & 30.0 & \\
\hline Satisfactory EHs & 189 & 46.1 & \\
\hline PA scores ${ }^{c}($ mean \pm SE) & & & $953.11 \pm 62.9$ \\
\hline Low activity & 131 & 32.0 & \\
\hline Moderate activity & 262 & 64.2 & \\
\hline Vigorous activity & 15 & 3.80 & \\
\hline Sitting hours/day (mean \pm SE) & & & $2.85 \pm 0.1$ \\
\hline
\end{tabular}

SE: stander error; ${ }^{\text {a }}$ Percentage may not total to $100 \%$ due to rounding; ${ }^{b}$ mean \pm SE, ${ }^{c}$ total Metabolic Equivalent-minutes/ week.

Table 3: Socio-demographic characteristics and lifestyle factors in non-pregnant Saudi women of reproduction age residing in Jeddah city, Saudi Arabia $(n=408)$

\section{Logistic regression analysis and overweight and obesity (BMI) risk factors}

A binary logistic regression was run to determine the effect of socio-demographic and lifestyle factors on risk of developing overweight and obesity (BMI) (Table 4). Overall, the analysis produced a significant model, Wald F (15) $=116.70, \mathrm{p}<0.001$, that correctly classified $74.7 \%$ of the cases, performing better in predicting obesity $(82.6 \%$ correctly predicted) than non-obesity (61.2\%). The model accounted for between 24.4\% (Cox and Snell) and 33.3\% (Nagelkerke) of the variance in obesity.

\begin{tabular}{|c|c|c|c|c|c|c|}
\hline Factors $^{a}$ & B & SE & Wald $x^{2}$ & $P$ value & Odds ratio & 95\%CI \\
\hline Fast Food Habit & 1.19 & 0.40 & 9.40 & .002 & .30 & $1.40-7.86$ \\
\hline Family History of obesity & 1.52 & 0.50 & 9.83 & .002 & 4.60 & $1.60-13.41$ \\
\hline Age (years) & 0.09 & 0.02 & 25.1 & $<.001$ & 1.10 & $1.05-1.14$ \\
\hline Eating Habit Scores & 0.08 & 0.03 & 6.00 & .015 & 1.08 & $1.01-1.16$ \\
\hline Constant & -2.60 & 1.45 & 4.73 & $<.001$ & 0.08 & $0.00-2.00$ \\
\hline Wald $x^{2}$ & \multicolumn{6}{|c|}{$116.70(\mathrm{df}=15)$} \\
\hline Cox and Snell pseudo $\mathbf{R}^{2}$ & \multicolumn{6}{|c|}{0.244} \\
\hline Nagelkerke pseudo $\mathbf{R}^{2}$ & \multicolumn{6}{|c|}{0.333} \\
\hline
\end{tabular}

BMI: Body Mass Index; B: Coefficient; SE: stander error; CI: confidence interval.

a Only significant factors are presented.

Table 4: Logistic regression model of general obesity (BM) risk factors in non-pregnant Saudi women of reproduction age residing in Jeddah city, Saudi Arabia $(n=408)$

The analysis showed that only four risk factors (predictors), were significantly associated with overweight and obesity as measured by BMI: age (years), family history of obesity, eating fast food, and eating habit score: odds ratios (ORs) of 1.10 (95\% CI 1.05-1.14; $\mathrm{P}<.001$ ), 4.6 (95\% CI 1.60-13.4; $\mathrm{p}=0.002$ ), 3.3 (95\% CI 1.40-7.86; $\mathrm{p}=0.002$ ), and 1.08 (95\% CI 1.01-1.16; $\mathrm{p}=0.015$ ), respectively. Women with family histories of obesity were 4.6 times more likely to be obese than those without family histories of obesity. Women with fast food habits were 3.3 times more likely to be obese than those without fast food habits. Each year increase in age 
is associated with a $10 \%$ increase in the likelihood of being obese. Each point increase on the eating habit scores is associated with an $8 \%$ increase in the likelihood of being obese.

\section{Multiple linear regression analysis and abdominal obesity (WC) risk factors}

A multiple linear regression was conducted to determine the association between the risk factors and the risk to developing abdominal obesity (WC). The analysis produced a significant model, Wald $\mathrm{x}^{2}(15)=304.0, \mathrm{p}<0.001$ and accounted for $39.7 \%$ of the variance in women's WC $\left(\mathrm{R}^{2}=0.397\right)$. The analysis showed that seven risk factors (predictors), were significantly associated with abdominal obesity (WC) (Table 5).

\begin{tabular}{|c|c|c|c|c|}
\hline Risk factors ${ }^{a}$ & B $(95 \% C I)$ & SE & Wald $x^{2}$ & $P$ value \\
\hline Constant & $51.74(30.94,67.68)$ & 9.02 & 35.51 & $<.001$ \\
\hline Age (years) & $0.63(0.37,0.89)$ & 0.12 & 28.98 & $<.001$ \\
\hline Income Status & $-4.74(-9.53,-0.05)$ & 2.15 & 4.85 & .028 \\
\hline Occupation Status & $-3.66(-6.62,-0.69)$ & 1.33 & 7.54 & .006 \\
\hline Family History of Obesity & $-9.32(-13.40,-5.24)$ & 1.83 & 25.90 & $<.001$ \\
\hline Eating Habit Scores & $0.41(0.14,0.68)$ & 0.12 & 11.60 & .001 \\
\hline Number of meals & $-2.90(-4.84,-0.95)$ & 0.87 & 11.03 & .001 \\
\hline Hours Sitting & $1.04(0.18,1.90)$ & 0.40 & 7.31 & .007 \\
\hline Wald $x^{2}$ & $304.90(\mathrm{df}=15)$ & & & $<.001$ \\
\hline $\mathbf{R}^{2}$ & 0.397 & & & \\
\hline
\end{tabular}

WC: waist circumference; B: Coefficient; CI: confidence interval; SE: stander error.

${ }^{a}$ Only significant factors are presented.

Table 5: Multiple-linear regression model of abdominal obesity (WC) risk factors in non-pregnant Saudi

women of reproduction age residing in Jeddah city, Saudi Arabia $(n=408)$

This model indicates positive associations between age (years), EHs, hours sitting, and abdominal obesity (WC). In contrast, the analysis showed that there were negative association between income status, occupation status, number of meals, and having a family history of obesity, and abdominal obesity (WC). Each additional year of age was associated with an increase of $0.63 \mathrm{~cm}$ in WC [95\% CI= 0.37 to 0.89 ], and each additional point on the EHs scale was associated with an increase of $0.41 \mathrm{~cm} \mathrm{in} \mathrm{WC} \mathrm{[95 \%} \mathrm{CI=}$ 0.14 to 0.68 ]. Each additional one-hour sitting was associated with an increase of $1.04 \mathrm{~cm}$ in WC [95\% CI=0.18 to 1.9 ]. Women Students have lower WC compared to housewives and employed women $(B=-3.66[95 \% \mathrm{CI}=-6.62$ to -0.69$])$, as well as women in higher-income levels have lower WC compared to women in low- and middle-income level women $(\mathrm{B}=-4.74[95 \% \mathrm{CI}=-9.53$ to 0.53$]$ ). Each additional meal was associated with a decrease of $2.9 \mathrm{~cm}$ in WC [95\% CI= -4.84 to -0.95 ]. Women without family histories of obesity have lower WC compared to women with family histories of obesity $(B=-9.32$ [95\% CI= -13.40 to -5.24$])$.

\section{Discussion}

\section{Prevalence of general and abdominal obesity}

Based on the WHO classifications, our findings on general obesity (BMI $\geq 30)$ among women of reproductive age are higher than those of the WHO publication for the Eastern Mediterranean Region [39], which reports a prevalence of obesity of $24 \%$, compared with $33.5 \%$ in our sample. Our study rates of overweight and obesity ( $29.5 \%$ and $33.8 \%$, respectively) are comparable to those reported by the latest National Saudi Health Information Survey (SHIS) (aged $\geq 16$ years) (28\% and 33.5\%, respectively) [3], lower than those reported by Al-Nozha et al. (2005) (31.8\% and 44\%, respectively), and higher than those estimated by Al-Othaimeen et al., (2007) (28.4\% and 23.4\%, respectively) in women 30-70 years old [9,7].

In terms of abdominal obesity (WC), there were a limited number of studies that examined the prevalence of abdominal obesity among Saudi women, specifically in reproductive age women. Comparing our rate of abdominal obesity (25.1\%) to two previous national surveys by Al-Saif et al. (2002) and Al-Nozha et al., (2005) among women in aged 30-70 years using WC cut-off point $(>88 \mathrm{~cm})$, indicated that their rates in women $(66.1 \%$, and $55.2 \%$ respectively) were much higher than our rates [40,41]. Also, our rate of abdominal obesity was lower than that of some other Middle East countries ( $\geq 20$ years of age), such as, Kuwait ( $\geq 20$ years of age), and Iran ( $\geq 15-65$ years of age) $(59.7 \% \& 53.2 \%$ respectively) $[42,43]$.

\section{Predictors of general and abdominal obesity}

Overall, multivariate regression analyses revealed that more predictors were associated with abdominal obesity than general obesity (overweight/obese). One factor that could lead to detection of more significant predictors was the choice to model WC continuously. Despite the high number of predictors, we found significant association with abdominal obesity; the two models had approximately equal explanatory or predictive power. The predictors in the linear regression model explained $39.7 \%$ of the variation in abdominal obesity, while in logistic regression explained between $24.4 \%$ (Cox \& Snell) and 33.3\% (Nagelkerke) of the variation in general obesity. 
The present study found age, family history of obesity, and EHs were significant predictors for both general and abdominal obesity, while fast food habit was a predictor for general obesity only. In terms of abdominal obesity alone, not having a family history of obesity, being a student, being in higher-income level, and eating three main meals had significant negative associations with abdominal obesity, while age, EHs, and hours sitting had significant positive associations with abdominal obesity. Education, marital status, parity, and consuming saturated fat were not significant predictors of either type of obesity.

Results from chi-square and the multivariate regression analyses confirmed the association between age, family history of obesity, and both types of obesity (dependent variables) in the study population. This finding has been found by other studies as well. Not surprisingly, age, which is related to marital status and parity, was a significant predictor of obesity in the study population. Among adult women (25-54years old) in Nairobi Province, Kenya, age was the most significant predictor of general and abdominal obesity [44]. A similar finding has been observed among both Jordanian women (aged 15-49 years) [45] and Iranian women (aged 35-57 years) [46]. Furthermore, in accordance with our results, family history of obesity has been recognized as an important predictor of obesity in several studies in Saudi Arabia [10,47], Jordon [48], and Iran [49]. A family history of obesity reflects the effects of shared genetics and environment among close relatives. Families cannot change their genes; however, they can change their family environment to encourage healthy EHs and PA behaviors. Such changes can improve the health of family members and improve the family health history of the future generation [50,51].

Among the four eating habit indicators, EHs score was a significant positive predictor for both types of obesity, eating fast foods was a significant positive predictor of general obesity, eating three meals per day was a significant positive predictor of abdominal obesity, while no significant association was found between consuming saturated fats and either type of obesity. Surprisingly, the significant positive associations between the EHs score and both types of obesity indicate that obese women have more good EHs than non-obese women. This finding differs from those of many other studies conducted in Saudi Arabia [10,47,52] and in Gulf countries [11]. However, the present paper found that women with high eating habit scores were more likely to be old, have medical health problems, and be less active than women with lower and medal scores. More than half of the women in the age group above 35 years reported medical health problems. Nearly, $91.6 \%$ of women who had diabetes, $92 \%$ of the women who had hypertension, and $87 \%$ of the women who had high cholesterol levels were obese. These women may be concerned about their EHs in order to reduce their weight and achieve related health goals, and therefore have higher eating habit scores. Also, women suffering from chronic health problems are more likely to receive health education from the health centers, which may improve their healthy eating knowledge, but does not seem to have the desired impact on PA. We found $31.2 \%$ ( $\mathrm{n}=59$ ) of the women with satisfactory EHs had low PA. This finding was consistent with a previous study that examined the inter-relationship between dietary habits, PA and health education provided at the PHCCs in the Qassim region of Saudi Arabia [53]. That study demonstrated that health education provided at the PHCC had a positive impact on dietary practices, but was not associated with increased PA. To be most effective in the long run, PHCC education programs should focus on promoting healthy eating as well as encouraging sustainable PA.

Most of the cross-sectional studies in free-living adults show an inverse relationship between eating frequency and adiposity [54]. The results of this study support these findings. We found a significant decrease in the risk of abdominal obesity with increasing number of meals in study population. Women who ate three main meals had lower WC than the women ate one or two meals per day. In a cross-sectional study on 7,958 Iranian adults, irregular meal pattern was also associated with greater odds of obesity. After adjustment for potential confounders, individuals with irregular meal patterns were more likely to have general and abdominal obesity, compared with those who had a regular meal pattern (ate 3 main meals per day) [55]. Numerous studies have established that low meal frequency is associated with higher 24-hour insulin concentrations when compared with high meal frequency. Eating multiple meals may suppress hunger and overall serum insulin concentrations. Furthermore, insulin inhibits lipolytic activity and increases fat deposition. As insulin is related to fatty acid storage, meal frequency may be one of the factors affecting body weight [56].

Scientific evidence indicates that fast food consumption is associated with higher total energy intake, as well as with weight gain and obesity [57]. In this study, a positive and significant association between fast food consumption and general obesity was confirmed among study population. Women who consumed fast food at least one a week were three more times as likely to be obese than those who had not. A cross sectional study among Michigan adults in the USA found a strong association between fast-food consumption and obesity prevalence; regular consumers of fast food had odds of being obese that were $60 \%$ to $80 \%$ higher than those for people who ate fast food less than once per week [58]. Overall, the prevalence of fast food among Michigan adults was lower than our rate, $28 \%$ and $84.7 \%$ respectively. Another study among 320 Kuwait college students found that regular consumption of fast food was the most significant predictor of obesity (OR 3.3, 95\% CI:1.3-8.9) (59). A cross-sectional study conducted to examine the pattern of fast food consumption among university students (18 to 25 years old) in King Faisal University, Al-Hassa, Saudi Arabia, using a logistic regression model, indicated a significant association between obesity/overweight and consuming fast food two or more times per week (OR=3.072, 95\% CI: 1.107-8.523) [60]. The percentage of those who consume fast food more than twice a week (47.1\%) was higher than in the present study $(38.2 \%)$. Globalization and westernization have contributed to the spread of fast food outlets in Saudi Arabia and home delivery services provided by fast food restaurants have contributed to a rise in the consumption of fast foods [61]. 
The association between socioeconomic status (SES) and obesity varies depending on each country's level of development and the SES indicators that are used [62]. In terms of indicators of socioeconomic status, such as income, occupational status, and years of education, we found associations between some of these indictors and abdominal obesity, but not with general obesity. Our study indicated a significant inverse association between abdominal obesity and income level. This finding was inconsistent with the findings of Al-Nozha et al. (2005) and Al-Saife et al. (2002) in Saudi women aged 30-70 years old; Al-Nozha indicated that income was a significant positive predictor of abdominal obesity and Al-Saife found an association with general obesity $[41,40]$. In our study, women at higher-income levels had lower mean WC compared to women at low-income levels, $76.7 \mathrm{~cm}$ and $80.7 \mathrm{~cm}$ respectively These findings could be due to women at higher-income levels being more active and having higher EHs score (healthy EHs) than women at low-income levels (PA means: 1440 vs 920 MET-Min/week, respectively; EHs score means: 39 vs 36, respectively). According to occupation status, we found that housewives were more likely to have abdominal obesity than students. In fact, high proportions of those housewives were less active, married, and had more children compared to students. In terms of education, data from the latest Saudi National survey found that high education level was associated with deceased risk of general obesity [3]. Khalid (2007) found a significant negative relationship between educational level and abdominal obesity among 438 currently married non-pregnant women (aged 18-60 years) in Abha City, Saudi Arabia [8]. However, the present study did not indicate any association between education and the two types of obesity. This may due to the fact that the majority of women in our study were educated (69\%), and had high school diploma or higher level of education, while the majority of the women in Khalid study were less educated; $81 \%$ of them had less than a high school diploma.

Lack of PA and sedentary behaviors are a major risk factor for obesity and many adverse health outcomes. A strong association between lack of PA and general and abdominal obesity has been observed in adolescents, males $(n=1400)$ and females $(n=1506)$ aged 14-19 years from three cities in Saudi Arabia (Al-Khobar, Jeddah and Riyadh) [52]. Data from the latest Saudi National survey found an association between general obesity and PA in men but not in women [3]. In the present study, we did not find any association between PA and the two types of obesity among the study population. However, we found positive significant association between times sitting and abdominal obesity. Women who sit more hours per day were at higher risk to have a large WC than women who sit fewer hours per day. The mean WC for women who sit 6 or more hours per day was much higher than for those who sit less than 6 hours $(92.7 \mathrm{~cm}$ and $79.4 \mathrm{~cm}$, respectively). Moreover, $87.6 \%$ of the women spent their time each day in sedentary behaviors (e.g. watching TV, phone, and computer use), and $99.2 \%$ of them used a car for transportation. Sedentary behaviors have also been shown to be independently associated with overweight and obesity. For example, in a population-based sample of Australian adults ( $\mathrm{n}=11,247$, aged $\geq 25$ years), a linear regression analysis showed that sitting time and TV viewing time were deleteriously associated with BMI, WC, and several biomarkers of cardio-metabolic risk in both women and men [63]. The link between sedentary behaviors and obesity are reduced leisure-time PA and increased energy intake [64]. In our study, women who spent more time sitting ( $\geq$ 6hours/day) tended to be less activity than those sitting fewer hours (Mean METs min/week: 467 vs 1050 , respectively).

\section{Study Strengths and Limitations}

Notable strengths of the study include the study design, study population, and a representative sample with a high response rate (96.2\%) to participate in the study. The study was selected from the most urbanized, liberal, diverse city in Saudi Arabia, Jeddah City. The sample was drawn from a large population to update the data on the prevalence of general (BMI) and abdominal (WC) obesity, and provide new data on factors associated with these two types of obesity. Moreover, taking a complex sample approach using specialized software resulted in unbiased parameter estimates, as well as robust standard errors that accurately reflect the variability in the population of interest.

An additional strength is that this is one of the first studies to examine risk factors associated with obesity among Saudi women of reproductive age in Jeddah City, as well as the first study that used combination measurements of WC and BMI categories to identify obesity risk factors among these women. It has been established that WC predicts obesity-related health risk, and the weighted evidence indicates that the addition of WC to BMI predicts a greater variance in health risk than does BMI alone [18]. At the same time, we are also aware of major limitations: this survey is cross-sectional; therefore, cause-and-effect cannot be determined for the associations between BMI or WC and their risk factors. Many of our behavioral data, such as EHs and PA, are self- reported and subject to reporting and social desirability biases.

\section{Conclusion}

The findings of the present study provide evidence that the prevalence of overweight, obesity, and abdominal obesity were remarkably high in non-pregnant Saudi women of reproductive age attending Jeddah PHCs. The present study found age, family history of obesity, and EHs were significant positive predictors for both general and abdominal obesity, while fast food habit was a significant positive predictor for general obesity only. Being a student, being in a higher-income level, and eating three main meals were the three factors with significant negative associations with abdominal obesity, while hours of sitting had significant positive associations. Education level(years), marital status, parity, and consuming saturated fat were not significant predictors of either type of obesity. Moreover, we found a significant association when using chi-square test between both types of obesity and age, parity, medical health problems, and family history of obesity. Our results highlight the need for further attention to 
the health and wellbeing of women of reproductive age in order to prevent the epidemic of obesity and related health problems. Health service providers should adopt, implement, and monitor policies that support healthy weight before and weight gain during pregnancy, and post natally through primary care physicians and obstetricians/gynecologists. An effective national obesity prevention strategy is needed and should start early, in the younger age groups, including health education regarding healthy EHs, avoiding high calorie fast-foods, encouraging PA, and reducing sedentary behaviors. Furthermore, healthcare practitioners should routinely collect family health histories to help to identify people at high risk of obesity-related diseases, and should therefore utilize every opportunity to include direct family members at risk in health education. An intervention that includes individuals at high-risk for developing obesity-related diseases and their families to promote lifestyle changes in their diet and PA is, therefore, a rational strategy that will contribute to the control and prevention of overweight and obesity-related health diseases in the reproductive age group.

\section{Acknowledgments}

The authors wish to thank the Jeddah Primary Health Centers (JPHCCs) that provided us the opportunity to conduct research at their facilities. We gratefully acknowledge the assistance of Professor James M. Lepkowski of the University of Michigan's Department of Biostatistics in helping design and select the sample of clinics, design the sample of eligible women within clinics, and develop suitable complex sample design estimation procedures, including nonresponse adjusted sampling weights.

\section{Appendix}

\section{References}

1. World Health Organization (WHO) (2011) Obesity and overweight. Fact sheet 311. Accessed on 09 May, 2012.

2. Low S, Chin MC, Deurenberg-Yap M (2009) Review on Epidemic of obesity. Ann Acd Med Singapore 38: 57-9.

3. Memish ZA, El Bcheraoui C, Tuffaha M, Robinson M, Daoud F, et al. (2013) Obesity and associated factors Kingdom of Saudi Arabia, 2013. Prev Chronic Dis. 11: E174.

4. Khashoggi RH, Madani KA, Ghaznawy HI, Ali MA (1994) Socioeconomic factors affecting the prevalence of obesity among female patients attending primary health centers in Jeddah, Saudi Arabia. Ecol Food Nutr 31: 277-83.

5. Al-Malki JS, Al-Jaser MH, Warsy AS (2003) Overweight and obesity in Saudi females of childbearing age. Int J Obes Relat Metab Disord 27: 134-39.

6. Marcinkevage JA, Alverson CJ, Narayan KM, Kahn HS, Ruben J, et al. (2013) Race/ethnicity disparities in dysglycemia among U.S. women of childbearing age found mainly in the nonoverweight/nonobese. Diabetes Care 36: 3033-9.

7. Al-Othaimeen AI, Al-Nozha M, Osman AK (2007) Obesity: an emerging problem in Saudi Arabia. Analysis of data from the National Nutrition Survey. East. Mediterr Health J 13: 441-8.

8. Khalid ME (2007) The prevalence of abdominal obesity and its associated risk factors in married, non-pregnant women born and living in high altitude, southwestern, Saudi Arabia. Saudi Med J 28: 1875-80.

9. Al-Nozha MM, Al-Mazrou YY, Al-Maatouq MA, Arafah MR, Khalil MZ, et al. (2005) Obesity in Saudi Arabia. Saudi Med J 26: 824-29.

10. Al-Qauhiz NM (2010) Obesity among Saudi Female University Students: Dietary Habits and Health Behaviors. J Egypt Public Health Assoc 85: 45-59.

11. Musaiger AO (2004) Overweight and obesity in the Eastern Mediterranean Region: can we control it? East Mediterr Health J 10: $789-93$.

12. Samir N, Mahmud S, Khuwaja AK (2011) Prevalence of physical inactivity and barriers to physical activity among obese attendants at a community health-care center in Karachi, Pakistan. BMC Research Notes 4: 174.

13. Washi SA, Ageib MB (2010) Poor diet quality and food habits are related to impaired nutritional status in 13- to 18-year-old adolescents in Jeddah. Nutr Res 30: 527-34.

14. Rasheed P (1998) Perception of body weight and self-reported eating and exercise behaviour among obese and non-obese women in Saudi Arabia. Public Health 112: 409-14.

15. Al-Nozha MM, Al-Hazzaa HM, Arafah MR, Al-Khadra A, Al-Mazrou YY, et al. (2007) Prevalence of physical activity and inactivity among Saudi population aged 30-70years. Saudi Med J 28: 559-68

16. Al-Quaiz AM, Tayel SA (2009) Barriers to a healthy lifestyle among patients attending primary care clinics at a university hospital in Riyadh. Ann Saudi Med 29: $30-5$.

17. Cornier MA, Després JP, Davis N, Grossniklaus DA, Klein S, et al. (2011) Assessing adiposity: a scientific statement from the American Heart Association. Circulation 124: 1996-2019.

18. Janssen I, Katzmarzyk PT, Ross R (2004) Waist circumference and not body mass index explains obesity-related health risk. Am J Clin Nutr 79: $379-84$.

19. Shields M, Tremblay MS, Connor Gorber S, Janssen I (2012) Abdominal obesity and cardiovascular disease risk factors within body mass index categories. Health Rep 23: 7-15.

20. Ravensbergen HR, Lear SA, Claydon VE (2014) Waist circumference is the best index for obesity-related cardiovascular disease risk in individuals with spinal cord injury. J Neurotrauma 31: 292-300.

21. Coutinho T, Goel K, Corrêa de Sá D, Kragelund C, Kanaya AM, et al. (2011) Central obesity and survival in subjects with coronary artery disease: a systematic review of the literature and collaborative analysis with individual subject data. J Am Coll Cardiol 57: 1877-86.

22. Browning LM, Hsieh SD, Ashwell M (2010) A systematic review of waist-to-height ratio as a screening tool for the prediction of cardiovascular disease and diabetes: 0.5 could be a suitable global boundary value. Nutr Res Rev 23: 247-69.

23. Hillemeier MM, Weisman CS, Chuang C, Downs DS, McCall-Hosenfeld J, et al. (2011) Transition to overweight or obesity among women of reproductive age. J Womens Health (Larchmt) 20: 703-10.

24. Turconi G, Guarcello M, Maccarini L, Cignoli F, Setti S, et al. (2008) Eating habits and Behaviors, physical activity, Nutritional and Food Safety Knowledge and Beliefs in an Adolescent Italian Population. J Am Coll Nutr 27: 31-43. 
25. Turconi G, Celsa M, Rezzani C, Biino G, Sartirana MA, et al. (2003) Reliability of a dietary questionnaire on food habits, eating behaviour and nutritional knowledge of adolescents. Eur J Clin Nutr 57: 753-63.

26. Soori H (2001) Pattern of dietary behaviour and obesity in Ahwaz, Islamic Republic of Iran. East Mediterr Health J 7: 163-70.

27. Al-Rethaiaa AS, Fahmy AE, Al-Shwaiyat NM (2010) Obesity and EHs among college students in Saudi Arabia: a cross sectional study. Nutr J 9: 39.

28. Dewar DL, Lubans DR, Plotnikoff RC, Morgan PJ (2012) Development and evaluation of social cognitive measures related to adolescent dietary behaviors. Int J Behav Nutr Phys Act 2: 36.

29. Arabic short version of International Physical Activity Questionnaire (2002) Stockholm, Karolinska Institutet.

30. Craig CL, Marshall AL, Sjöström M, Bauman AE, Booth ML, et al. (2003) International physical activity questionnaire: 12-country reliability and validity. Med Sci Sports Exerc 35: 1381-95.

31. Al-Hazzaa HM (2007) Health-enhancing physical activity among Saudi adults using the International Physical Activity Questionnaire (IPAQ). Public Health Nutr 10: 59-64.

32. Al-Eisa E, Al-Sobayel H (2012) Physical Activity and Health Beliefs among Saudi Women. J Nutr Metab $2012: 642187$.

33. AboZaid HA \& Farahat FM (2010) Physical activity profile among patients attending family medicine clinics in western Saudi Arabia. Saudi Med J 31: 428-33. 34. Al-Hazzaa HM (2004) The public health burden of physical inactivity in Saudi Arabia. J Family Community Med 11: 45-51.

35. International Physical Activity Questionnaire (2005) Guidelines for data processing and analysis of the International Physical Activity Questionnaire (IPAQ). 36. World Health Organization (2012) Global Database on Body Mass Index. BMI classification.

37. De Onis M, Onyango AW, Borghi E, Siyam A, Nishida C, et al. (2007) Development of a WHO growth reference for school-aged children and adolescents. Bull World Health Organ 85: 660-7.

38. World Health Organization (2010) Anthro plus for personal computers, version 3.3.2, 2011: Software for assessing growth and development of the world's children. Geneva: WHO.

39. World Health Organization (WHO) (2014) Global Health Observatory. Obesity: Situation and trends.

40. Al-Saif M A, Hakimb IA, Harrisc RB, Al-duwaihyd M, Al-Rubeaand K, et al. (2002) Prevalence and risk factors of obesity and overweight in adult Saudi population. Nutrition Research 22: 1243-52.

41. Al-Nozha M, Al-Khadra A, Arafah MR, Al-Maatouq MA, Khalil MZ, et al. ( 2005) Metabolic syndrome in Saudi Arabia. Saudi Med J 26: 1918-25.

42. Al-Zenki S, Al-Omirah H, Al Hooti S, Al-Hamad N, Jackson RT, et al. (2012) High prevalence of metabolic syndrome among Kuwaiti adults--a wake-up call for public health intervention. Int J Environ Res Public Health 9: 1984-96.

43. Veghari G, Sedaghat M, Banihashem S, Moharloei P, Angizeh A, et al. (2012) Trends in waist circumference and central obesity in adults, northern iran. Med J 27: 50-3.

44. Mbochi RW, Kuria E, Kimiywe J, Ochola S, Steyn NP (2012) Predictors of overweight and obesity in adult women in Nairobi Province, Kenya. BMC Public Health 12: 823 .

45. Al-Nsour M, Al Kayyali G, Naffa S (2013) Overweight and obesity among Jordanian women and their social determinants. East Mediterr Health J 19: 1014-9. 46. Nouhjah S, Nadi-baghu M, Salehi M (2012) Ghajari H. Prevalence of Overweight, Obesity and the Related Factors in Women Aged 35-57 Years in Khuzestan Province of Iran. Advanced Studies in Biology 4: 57-65.

47. Issa LF (2015) Prevalence and risk factors of obesity and overweight among Taif University Students, Taif, Saudi Arabia. Int J Public Health 4: 98 -106.

48. Suleiman AA, Albooai OK, Yasein N, El- Oudah JM (2009) Prevalence and factors associated with overweight and obesity among Jordan university students. J Bio Sc 9: 738-45.

49. Hajian-Tilaki KO, Heidari B (2007) Prevalence of obesity, central obesity and the associated factors in urban population aged 20-70 years, in the north of Iran: a population-based study and regression approach. Obes Rev 8: 3-10.

50. Bouchard C (2010) Defining the genetic architecture of the predisposition to obesity: a challenging but not insurmountable task. Am J Clin Nutr 91: 5-6.

51. Choquet H, Meyre D (2011) Genetics of obesity: what have we learned? Curr Genomics 12: 169-79.

52. Al-Hazzaa HM, Abahussain NA, Al-Sobayel HI, Qahwaji DM, Musaiger AO (2012) Lifestyle factors associated with overweight and obesity among Saudi adolescents. BMC Public Health 16: 354.

53. Midhet F, Al Mohaimeed AR, Sharaf F (2010) Dietary practices, physical activity and health education in Qassim region of Saudi Arabia. Int J Health Sci 4: 3-10. 54. McCrory MA, Howarth NC, Roberts SB, Huang TT (2011) Eating frequency and energy regulation in free-living adults consuming self-selected diets. J Nutr 141: $148-53$.

55. Saneei P, Esmaillzadeh A, Keshteli AH, Feizi A, Feinle-Bisset C, et al. (2016) Patterns of dietary habits in relation to obesity in Iranian adults. Eur J Nutr 55: 713-28.

56. Ma Y, Bertone ER, Stanek EJ, Reed GW, Hebert JR, et al. (2003) Association between eating patterns and obesity in a free-living US adult population. Am J Epidemiol 15: 85-92.

57. Asghari G, Yuzbashian E, Mirmiran P, Mahmoodi B, Azizi F (2015) Fast Food Intake Increases the Incidence of Metabolic Syndrome in Children and Adolescents: Tehran Lipid and Glucose Study. PLoS ONE 10: e0139641.

58. Anderson B, Rafferty AP, Lyon-Callo S, Fussman C, Imes G (2011) Fast-food consumption and obesity among Michigan adults. Prev Chronic Dis 8: A71.

59. El-Ghazali S, Ibrahim JM, Kandari BM, Ismail NA (2010) The Relationship between Lifestyle and Body Mass Index Among University Students in Kuwait. The Egyptian J of Community Med 28.

60. Al-Otaibi HH, Basuny AM (2015) Fast Food Consumption Associated with Obesity/Overweight Risk among University Female Student in Saudi Arabia. Pak. J. Nutr 14: 511-16.

61. Musaiger AO, Al-Mannai M, Zagzoog N (2014) Association between food intake frequency and obesity among adolescent girls in Saudi Arabia. Int J Adolesc Med Health 26: 145-7.

62. Jin MJ, Chen BB, Mao YY, Zhu YM, Yu YX et al. (2013) Prevalence of overweight and obesity and their associations with socioeconomic status in a rural Han Chinese adult population. PLoS One 8: e79946. 
63. Thorp AA, Healy GN, Owen N, Salmon J, Ball K et al. (2010) Deleterious associations of sitting time and television viewing time with cardiometabolic risk biomarkers: Australian Diabetes, Obesity and Lifestyle (AusDiab) study 2004-2005. Diabetes Care 33: 327-34.

64. Shields M, Tremblay MS (2008) Sedentary behaviour and obesity. Health Rep 19: 19-30.

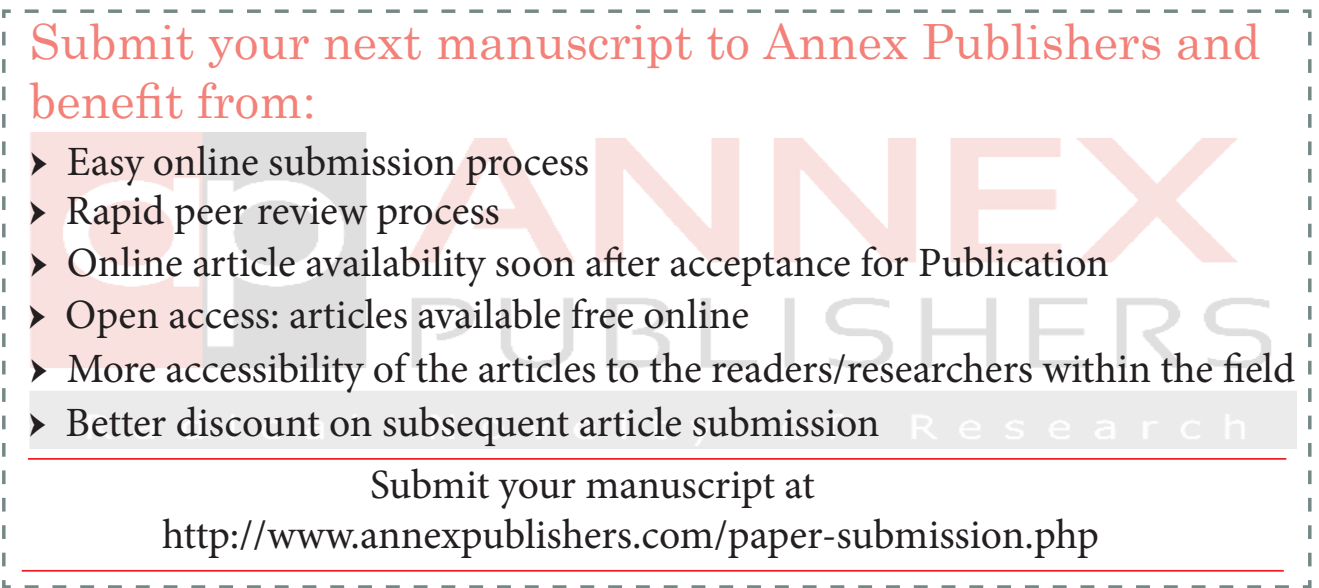

